\title{
Technological challenges in the preclinical development of an HIV nanovaccine candidate
}

Tamara G. Dacoba ${ }^{1,2}$, Luisa Ruiz-Gatón ${ }^{3}$, Ana Benito ${ }^{3}$, Marlène Klein ${ }^{4}$, Damien Dupin ${ }^{3}$, Ma Luo ${ }^{5}$, Mathieu Menta ${ }^{4}$, Desirée Teijeiro-Osorio ${ }^{1,2}$, Iraida Loinaz ${ }^{3}$, María J. Alonso ${ }^{1,2^{*}}$, José CrecenteCampo $^{1,2^{*}}$

${ }^{1}$ Center for Research in Molecular Medicine and Chronic Diseases (CIMUS), IDIS research Institute, Universidade de Santiago de Compostela, Santiago de Compostela 15782, Spain.

${ }^{2}$ Department of Pharmacology, Pharmacy and Pharmaceutical Technology, School of Pharmacy, Campus Vida, Universidade de Santiago de Compostela, Santiago de Compostela 15782, Spain.

${ }^{3}$ CIDETEC, Basque Research and Technology Alliance (BRTA), Parque Científico y Tecnológico de Gipuzkoa, Donostia-San Sebastián 20014, Spain

${ }^{4}$ Ultra Trace Analyses Aquitaine (UT2A/ADERA), Technopôle Hélioparc Pau-Pyrénées, Pau 64053 cedex 9, France

${ }^{5}$ Department of Medical Microbiology and Infectious Diseases, University of Manitoba, Winnipeg, MB, Canada.

${ }^{*}$ Co-corresponding authors.

Co-corresponding authors email address: mariaj.alonso@usc.es jose.crecente@usc.es

This is a post-peer-review, pre-copyedit version of an article published in Drug Delivery and Translational Research. The final authenticated version is available online at: http://dx.doi.org/10.1007/s13346-020-00721-8. 


\begin{abstract}
Despite a very active research in the field of nanomedicine, only a few nano-based drug delivery systems have reached the market. The "death valley" between research and commercialization has been partially attributed to the limited characterization and reproducibility of the nanoformulations. Our group has previously reported the potential of a peptide-based nanovaccine candidate for the prevention of SIV infection in macaques. This vaccine candidate is composed of chitosan/dextran sulfate nanoparticles containing twelve SIV peptide antigens. The aim of this work was to rigorously characterize one of these nanoformulations containing a specific peptide, following a quality-by-design approach. The evaluation of the different quality attributes was performed by several complementary techniques, such as dynamic light scattering, nanoparticle tracking analysis and electron microscopy for particle size characterization. The inter-batch reproducibility was validated by three independent laboratories. Finally, the long-term stability and scalability of the manufacturing technique were assessed. Overall, these data, together with the in vivo efficacy results obtained in macaques, underline the promise this new vaccine holds with regard to its translation to clinical trials.
\end{abstract}

Keywords: HIV; quality-by-design; scale-up; microfluidics; industrial translation; nanoparticles 
Graphical abstract

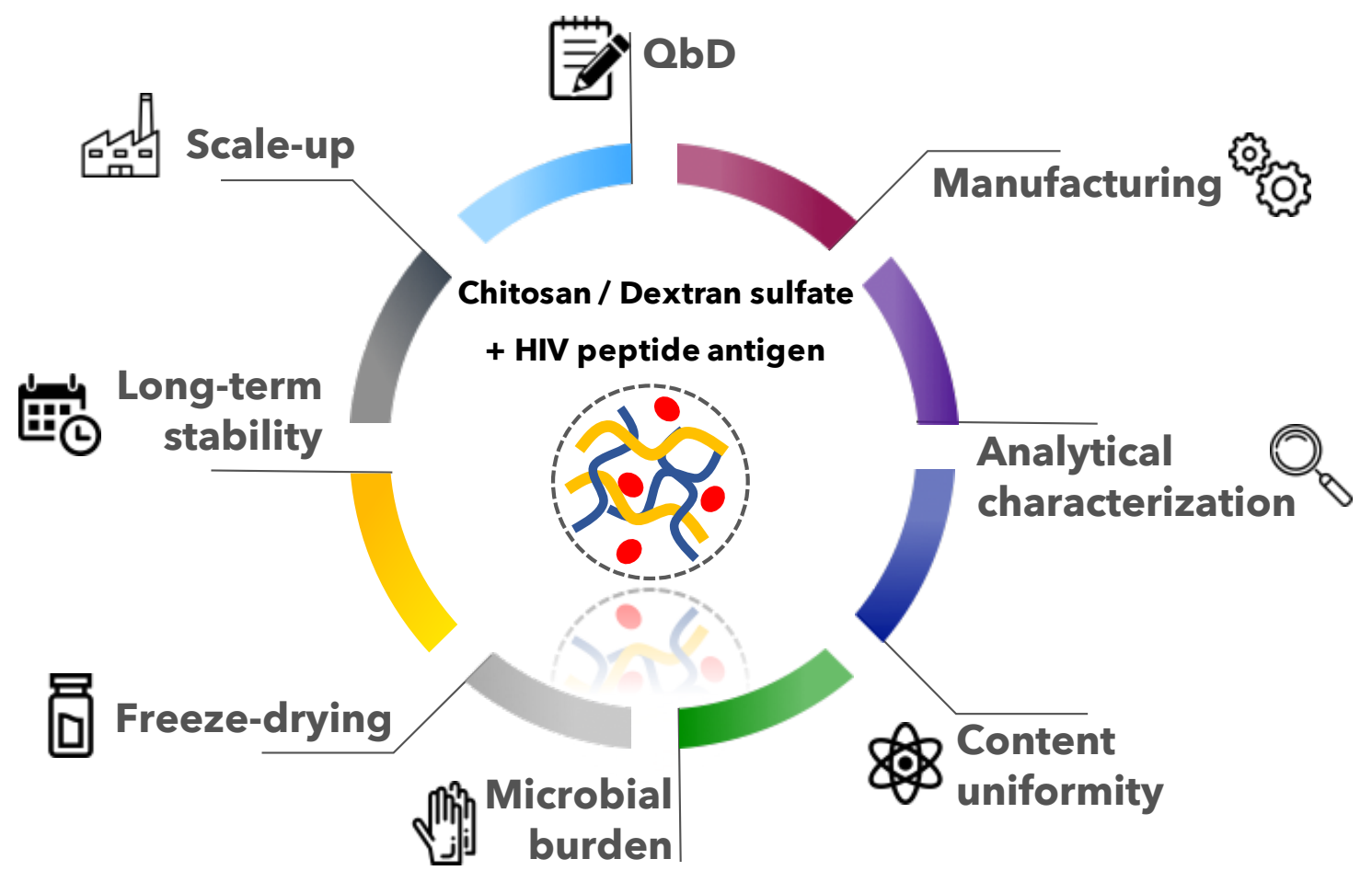




\section{Introduction}

In the last decades, nanotechnology has shown a great potential for the delivery of complex biomolecules [1-8] and particularly antigens [9-12]. Advances in this field have led to the clinical approval of a few tens of nanoformulations [13-15], and to the evaluation of many more in clinical trials $[11,14]$. Regardless of the type of formulation, nanomedicines are usually complex systems, where small changes in their production or composition can result in a decreased efficacy and, often, undesired side effects [16]. This complexity is also one of the main reasons that has hindered the commercialization of nanotechnology-based drugs $[17,18]$. For example, Couvreur et al. have recently reported the challenges faced during the scale-up of squalene-adenosine NPs and the important differences in the physicochemical properties of lab- and industrial-scale batches [19]. Therefore, a detailed analytical characterization of the nanomedicines is a critical step to identify their most important manufacturing features, and to ensure their reproducibility, therapeutic efficacy and safety $[16,20]$.

Pharmaceutical quality-by-design $(\mathrm{QbD})$ is a systematic approach that begins by predefining the characteristics of the targeted formulation. It is based on implementing statistical, analytical and riskmanagement methods in order to understand the product and the processes involved in its fabrication [21]. The application of $Q b D$ is essential to guarantee the safety and efficacy of a formulation [21-24]. In addition, the knowledge generated through these approaches represents critical information to be considered by the regulatory authorities. The increasing application of $\mathrm{QbD}$ approaches for the development of nanoformulations will certainly contribute to generate more robust formulations [2530]. Additionally, as indicated by the MIRIBEL recommendations [31], the report of a minimum information about nano-delivery systems in terms of material and biological characterization, together with the experimental protocol details, will be another key aspect in the generation of more robust nanomedicines.

Despite the important advances achieved in vaccination through the use of nanotechnology, still many infectious diseases (i.e., HIV, malaria or tuberculosis) remain elusive to vaccination [11]. Our group has dedicated significant efforts to the development of effective nanovaccines for different infectious diseases [32-35]. All this knowledge brought us to develop, in collaboration with investigators of the University of Manitoba, a potential HIV vaccine candidate based on polysaccharide nanoparticles (NPs) [36-38]. The vaccine is composed of twelve different small peptide antigens that target the protease cleavage sites (PCS) of the virus, that are associated to chitosan/dextran sulfate (CS/DS) NPs [36,38]. The promising results reported in macaques encouraged us to optimize and adapt the 
nanoformulation for its production in a pilot plant for preclinical and, potentially, future clinical trials [36]. Considering that the formulation process for each of the peptides is the same, the technology transfer process was validated for the NPs containing only one peptide antigen (PCS5). For this purpose, and within the frame of the European Horizon 2020 project NANOPILOT, several research groups were involved in the development of the methods, techniques and a pilot plant to produce the nanovaccine. This work compiles part of the results generated within this consortium. Thus, in the following sections, we report the adaptation of the manufacturing procedure of an HIV nanovaccine candidate for its production in a pilot plant. The use of the $\mathrm{QbD}$ methodology involved the identification of the target product profile of the selected prototype, its critical quality attributes, and a risk analysis based on an Ishikawa diagram. Then, the influence of the manufacturing parameters on the final properties of the nanoformulation was assessed. A thorough characterization using orthogonal techniques was carried out in order to define the attributes of the nanoformulation. Finally, different scaling-up methodologies and an interlaboratory manufacturing transfer were conducted to study the translational potential of these polymeric NPs to an industrial environment.

\section{Materials and Methods}

\subsection{Materials}

Chitosan (CS) (hydrochloride salt, molecular weight (MW) $42.7 \mathrm{KDa}$ and 88\% deacetylation degree) was obtained from $\mathrm{HMC}^{+}$(Halle, Germany). Dextran sulfate (DS), (sodium salt, MW 8 KDa) was purchased from Dextran Products Ltd (ON, Canada). High purity $\alpha, \alpha$-trehalose dihydrate was purchased from Pfanstiehl (IL, USA). HIV PCS5 peptide (sequence GPWGKKPRNFPMAQVHQGLM, MW 2280 Da and $>95 \%$ purity) was obtained from GenScript (NJ, USA).

\subsection{Quality-by-design (QbD)}

The quality target product profile (QTTP) and critical quality attributes (CQAs) of the nanoformulation were established based on previous knowledge, and recommendations from the International Conference on Harmonisation of Technical Requirements for Registration of Pharmaceuticals for Human Use (ICH), European Medicines Agency (EMA) and US Food and Drug Administration (FDA) $[39,40]$; and are summarized in Table 1 and Table 2. For the risk analysis, experts in different fields agreed on the design of an Ishikawa diagram and identified the most critical parameters that could have an effect on the nanoformulation CQAs (Fig. 1) [40]. 


\subsection{Nanoparticle preparation}

CS/DS NPs were prepared as previously described [36,37]. Briefly, $0.770 \mathrm{~mL}$ of a CS aqueous solution $(0.67 \mathrm{mg} / \mathrm{mL})$ were added to a test tube under mild magnetic stirring. A volume of $0.055 \mathrm{~mL}$ of PCS5 in aqueous solution ( $4 \mathrm{mg} / \mathrm{mL}$ ) was then added with a pipette. After $5 \mathrm{~min}$ of stirring, $0.825 \mathrm{~mL}$ of a DS aqueous solution $(1.875 \mathrm{mg} / \mathrm{mL})$ were added. The solution was stirred for 5 additional $\mathrm{min}$, and the formulation was left standing for 10 min prior to characterization. For the preparation of blank NPs, the solution of PCS5 was replaced by ultrapure water.

\subsection{Nanoparticle freeze-drying}

A volume of $180 \mu \mathrm{L}$ of trehalose $45 \%$ (wt) was added to $900 \mu \mathrm{L}$ of NPs, mixed by horizontal shaking for at least $20 \mathrm{~min}$, frozen at $-80^{\circ} \mathrm{C}$ for $2 \mathrm{~h}$, and then freeze-dried (Genesis ${ }^{\mathrm{TM}} 25 \mathrm{EL}, \mathrm{S} . \mathrm{P}$ Industries, PA, USA). Samples were first left in the freeze-drier at $-40^{\circ} \mathrm{C}$ for $4 \mathrm{~h}$ to guarantee that they were completely frozen, with a vacuum of 200 mTorr. Then, the first drying phase was done at a temperature ranging from $-40{ }^{\circ} \mathrm{C}$ to $+20^{\circ} \mathrm{C}$, applying a progressive vacuum to $20 \mathrm{mTorr}$ for a period of $43 \mathrm{~h}$. Finally, the secondary drying phase was done for $3 \mathrm{~h}$ at $+22^{\circ} \mathrm{C}$ and 20 mTorr. At pre-determined times, the final cake was reconstituted in ultrapure water and NPs were conveniently characterized.

\subsection{Nanoparticle characterization}

\subsubsection{Dynamic Light Scattering (DLS)}

The mean particle size (Z-average) and polydispersity index (PDI) of the non-diluted samples were characterized by DLS, following ISO standards [41]. The zeta potential values were determined by Laser Doppler Anemometry (LDA), measuring the mean electrophoretic mobility after a 10-times dilution of the NPs in ultrapure water. Derived count rate represents the scattering intensity measured in the absence of a laser light attenuation filter, and it was calculated as the ratio between the measured count rate and the attenuation factor. At USC and CIDETEC, these properties were measured using a Zetasizer ${ }^{\circledR}$ NanoZS, using the software Zetasizer v7.13 (Malvern Panalytical Ltd., Malvern, UK), at $25^{\circ} \mathrm{C}$ and a detection angle of 173. At UT2A, DLS measurements were done in a VASCO-2 particle size analyzer (Cordouan Technology, France) in combination with the software nanoQ v 6.2.2, at $25^{\circ} \mathrm{C}$ and a detection angle of 135 .

\subsubsection{Electron microscopy}

Field Emission Scanning Electron Microscopy (FESEM) (Zeiss Gemini Ultra Plus, Oberkochen, Germany) was used for morphology evaluation. Reconstituted freeze-dried NPs were diluted 1:100 in water, and 
then diluted 1:1 with phosphotungstic acid ( $2 \%$ in water). $1 \mu \mathrm{L}$ of sample was placed on a copper grid with carbon films and, once dried, washed with $1 \mathrm{~mL}$ of ultrapure water. When dried, samples were analyzed under the microscope using a STEM detector. ImageJ software was used for NP counting and analysis ( $\mathrm{n} \approx 100$ ), by employing the Analyze/Analyze Particles command, in accordance to an already described method [42].

\subsubsection{Nanoparticle tracking analysis (NTA)}

Reconstituted freeze-dried NPs were diluted 1:1000 in ultrapure water prior to analysis in a Nanosight NS300 (Malvern Panalytical Ltd., Malvern, UK) using the Nanosight NTA software v3.3. The camera gain was set at 11 or 13 . Each sample was measured 5 times for 60 s each.

\subsection{4. $\mathrm{pH}$, osmolality, \% of transmittance and moisture}

A freshly calibrated Sartorius Docu-pH Benchtop Meters (Thermo Fisher Scientific, MA, USA) was employed for the determination of the $\mathrm{pH}$ of the formulation at USC. A GLP2 pH-meter (Crison Scharlab, Barcelona, Spain) was used in CIDETEC for the determination of the $\mathrm{pH}$ of the final product. Osmolality was measured in a Gonotec Osmomat 030 Cryoscopic Osmometer (Gonotec GmbH, Berlin, Germany) at USC, or in a vapor pressure osmometer model 5600 Vapor (Wescor Vapro, Utah, USA) at CIDETEC. The values of percentage of transmittance were obtained either from a DU ${ }^{\otimes 730 ~ U V / V i s ~}$ Spectrophotometer (Beckman-Coulter, CS, USA) at USC, or from a UV-Visible spectrophotometer Shimazdu UV-2401PC (Shimazdu, Kyoto, Japan) at CIDETEC, both at a wavelength of $236 \mathrm{~nm}$. The water content was determined by Karl-Fischer titration (Metrohm 899, Herisau, Switzerland).

\subsection{Filtration}

Millex ${ }^{\circledR}$-GV filters (Millipore Corporation, MA, USA), of 13 - or 33-mm diameter and $0.22 \mu \mathrm{m}$ pore size of polyvinylidene fluoride (PVDF), polyethylene sulfone (PES) or polytetrafluoroethylene (PTFE) were used to filter NPs or polymer solutions. A volume of $0.5 \mathrm{~mL}$ of nanoformulation or $20 \mathrm{~mL}$ of polymer solution was injected through the filters, discarding the first drops, following the supplier recommendation. 


\subsection{Peptide PCS5 quantification}

\subsubsection{Particle disassembling}

For the particle disruption process, NPs were diluted in a 1:1 $(\mathrm{v} / \mathrm{v})$ ratio with the solution of $\mathrm{KCl}$, and the derived count rate determined by DLS. As a control, NPs were diluted in the same proportion with water.

\subsubsection{UPLC analysis}

At USC, samples were analyzed by Ultra Performance Liquid Chromatography (UPLC) on an Acquity HUPLC Class system with a UV detector at $280 \mathrm{~nm}$ (Waters Corporation, MA, USA) equipped with an Aeris $3.6 \mu \mathrm{m}$ Widepore XB-C18 LC $100 \times 2.1 \mathrm{~mm}$ Column (Phenomenex, CA, USA), as previously described [37]. Briefly, mobile phases $A$ and $B$ consisted of $0.1 \%$ trifluoroacetic acid ( $v / v)$ in either ultrapure water or acetonitrile HPLC grade, respectively. Column temperature was set at $30{ }^{\circ} \mathrm{C}$, and the run from $10 \%$ to $100 \%$ of phase B in $5 \mathrm{~min}$, and $3 \mathrm{~min}$ to $10 \%$. A calibration curve generated with known concentrations of the peptide, both in water and in the disassembled NPs $\left(6.5-100 \mathrm{mg} / \mathrm{L}, \mathrm{R}^{2}=\right.$ 0.99) was used to quantify the amount of PCS5 in each sample.

At CIDETEC, the quantification of the peptide was carried out using a High Performance Liquid Chromatography (HPLC), in an Agilent model 1100 series LC with UV detector, the ChemStation software (Agilent Technologies, CA, USA) and with a X Bridge BEH C18 $2.5 \mu \mathrm{m} 4.6$ x $100 \mathrm{~mm}$ column (Waters Corporation, MA, USA). Mobile phases A and B consisted of $0.1 \%$ trifluoroacetic acid $(\mathrm{v} / \mathrm{v})$ in either ultrapure water or acetonitrile HPLC grade, respectively. Column temperature was set at $30^{\circ} \mathrm{C}$, and the run from $10 \%$ to $100 \%$ of phase $B$ in $12 \mathrm{~min}$ at flow rate of $0.65 \mathrm{~mL} / \mathrm{min}$. A calibration curve generated with known concentrations of the peptide, in water and in the disassembled NPs $(6.5-100$ $\mathrm{mg} / \mathrm{L}, \mathrm{R}^{2}=0.99$ ) was used to quantify the amount of PCS5 in each sample.

At UT2A, samples were analyzed with an Agilent 1260 series autosampler and a HPLC pump (Agilent Technologies, CA, USA) equipped with a Superdex peptide 10/300GL column (GE Healthcare, IL, USA) and an UV-Visible detector operating at 214 nm (VWD 1200 series, Agilent Technologies, CA, USA), as already reported [43]. In this case, peptide elution was done with $50 \mathrm{mM}$ phosphate buffer and 150 $\mathrm{mM}$ sodium chloride, with flow rate of $0.7 \mathrm{~mL} / \mathrm{min}$ for $35 \mathrm{~min}$. Calibration was obtained with peptide concentrations ranging from 10 to $100 \mathrm{mg} / \mathrm{L}\left(\mathrm{R}^{2}>0.995\right)$, prepared in $\mathrm{NaOH} 0.1 \mathrm{M}$. 


\subsection{Scale-up}

\subsubsection{Microfluidics}

A NanoAssemblr microfluidics device (Precision nanosystems, Vancouver, Canada) was used for the preparation of the NPs. The cartridges used were $200 \mu \mathrm{m}$ wide and $79 \mu \mathrm{m}$ high, while the mixing area had a herringbone structure that was $31 \mu \mathrm{m}$ high and $50 \mu \mathrm{m}$ thick. To assess the influence of the total flow rate, flows ranging from $0.5 \mathrm{~mL} / \mathrm{min}$ to $14 \mathrm{~mL} / \mathrm{min}$ were used, with initial polymer concentrations of $0.63 \mathrm{mg} / \mathrm{mL}$ of CS and $1.875 \mathrm{mg} / \mathrm{mL}$ of DS and a 1:1 flow ratio. For the loaded NPs, the CS solution had a PCS5 concentration of $0.27 \mathrm{mg} / \mathrm{mL}$. NPs were characterized by DLS.

\subsubsection{Batch-mode}

For the preparation of $200 \mathrm{~mL}$ batches, a propeller stirrer IKA RW 20 (Staufen, Germany; 4-blade, stir diameter $50 \mathrm{~mm}$, shaft diameter $8 \mathrm{~mm}$, and shaft length $350 \mathrm{~mm}$ ) was used to mix the different solutions. To $93.3 \mathrm{~mL}$ of an aqueous solution of CS $(0.67 \mathrm{mg} / \mathrm{mL}), 6.7 \mathrm{~mL}$ of either ultrapure water or an aqueous solution of PCS5 $(4 \mathrm{mg} / \mathrm{mL})$ were added under stirring at $700 \mathrm{rpm}$, and let to mix for $5 \mathrm{~min}$. Then, $100 \mathrm{~mL}$ of an aqueous solution of DS $(1.875 \mathrm{mg} / \mathrm{mL})$ were poured onto the CS/PCS5 solution, kept under stirring for $5 \mathrm{~min}$ and standing for $10 \mathrm{~min}$. Supplementary Video $\mathbf{S 1}$ shows the formulation procedure of the loaded NPs.

\subsection{Statistical analysis}

Data analysis was performed with GraphPad Prism version 7.0 (GraphPad Inc). Statistical comparison was done using ANOVA, followed by a Dunnett's multiple comparison test. Data are expressed as the mean \pm standard deviation (SD). $p$ values of 0.05 or less were considered statistically significant.

\section{Results and Discussion}

The complexity of some nanoformulations and the lack of well-defined standard analytical methodologies for their complete characterization are some of the hurdles that have hampered the arrival of nanomedicines to the market [17]. In fact, these difficulties for the translation of NPs preparation technique from a lab to an industrial scale were recently described in a report by Couvreur el al. [19]. Therefore, it has become clear that the assessment of reproducibility and the selection of adequate characterization methods are critical steps to be considered in the scientific literature. Here, our aim was to transfer the development of a potential nanovaccine candidate from the bench to an 
industrial environment, highlighting the critical requirements that all nanovaccine candidates should fulfill in order to progress towards commercialization.

\subsection{Implementation of a quality-by-design approach}

The aim of a QbD approach is to understand how the formulation and processing parameters affect the properties of the formulation. This knowledge is critical in order to generate more robust and reproducible nanomedicines [44]. Here, the quality target product profile (QTPP) of the nanoformulation was first established (Table 1), following ICH recommendations [40]. The QTPP was determined by the indication and the modality of administration. In this sense, based on the positive data obtained in macaques $[36,38]$, the product was defined for vaccination against HIV and for intranasal administration (Table 1). In order to maintain the long-term stability, the product was formulated as a freeze-dried powder that could be rapidly dispersed in water at the moment of administration (Table 1).

Table 1 Quality Target Product Profile (QTPP) of the HIV vaccine candidate

\begin{tabular}{|c|c|c|}
\hline Parameter & Target & Justification \\
\hline Indication & HIV vaccine & PCS5 has been reported to be one potential antigen in HIV [45] \\
\hline $\begin{array}{l}\text { Route of } \\
\text { administration }\end{array}$ & Nasal & $\begin{array}{l}\text { Good preliminary results through this route, improves patient } \\
\text { compliance [36] }\end{array}$ \\
\hline Dosage form & Freeze-dried powder & To increase long-term stability \\
\hline API content & $100 \mu \mathrm{g} / \mathrm{mL}$ & Required antigen dose for macaque studies \\
\hline Packaging & Type I glass vials & $\begin{array}{l}\text { Recommended by USP and Eur. Ph. for injectable formulations } \\
\text { and able to resist thermal shocks (for freeze-drying) }\end{array}$ \\
\hline Stability & $\begin{array}{l}\text { At least } 1 \text { year at room } \\
\text { temperature }\end{array}$ & To guarantee an acceptable stability \\
\hline Dispersibility & $\begin{array}{l}\text { In } 10 \mathrm{~s} \text {, by manual } \\
\text { shaking }\end{array}$ & $\begin{array}{l}\text { To facilitate self-preparation and administration - no need of } \\
\text { training or specialized equipment }\end{array}$ \\
\hline Moisture & $<3 \%$ & To avoid API degradation or bacterial growth \\
\hline
\end{tabular}

As a second step, the critical quality attributes (CQAs) were defined (Table 2). CQAs are the main physical, chemical and biological attributes, which are critical to guarantee the safety and efficacy of the nanoformulation (Table 2) [39]. These details were gathered from the knowledge our research group has from working on the development of this type of nanocarriers, from the specific recommendations from the FDA and the EMA, and also from the different Pharmacopeias. More precisely, both the composition of the CS/DS NPs and the antigen dose selected were already tested 
in vivo, with promising results $[36,38]$. Indeed, CS and DS are two polysaccharides used in nanovaccines due to their biocompatibility, biodegradability, and low toxicity, and that have also shown to improve the immune response against many antigens [35,46-49]. Furthermore, CS has an FDA GRAS status. The values of the physicochemical properties of the NPs were based on the literature, where nanometric sizes have been shown to perform better than micrometric sizes for the delivery of biomolecules through the nasal route [50]. Within the nanometric range, medium size NPs (200 nm) elicited stronger responses than very small sizes $(30 \mathrm{~nm})$ [51]. In terms of the surface charge, it is important to find a balance between mucoadhesion and mucodiffusion [11]. Finally, values as osmolality, $\mathrm{pH}$, moisture and microbiology have been selected from the literature and FDA recommendations [52-54]. 
Table 2 Critical quality attributes (CQAs) of the formulation

\begin{tabular}{|c|c|c|}
\hline CQAs & Target & Justification \\
\hline Components & $\begin{array}{l}\text { Dextran sulfate, sodium salt } \\
\text { Chitosan, hydrochloride salt } \\
\text { Peptide antigen (PCS5) } \\
\text { Highly purified water (type I) }\end{array}$ & $\begin{array}{l}\text { Materials of the original formulation; water for } \\
\text { parenteral administration }[36,38]\end{array}$ \\
\hline Content uniformity & $82.25 \mathrm{mg} \pm 10 \%$ & Amount needed for an adequate dosing of API \\
\hline API content & $100 \mu \mathrm{g} / \mathrm{mL}$ & Dose used in macaques $[36,38]$ \\
\hline $\begin{array}{l}\text { Particle size and } \\
\text { distribution }\end{array}$ & $\begin{array}{l}100-300 \mathrm{~nm} \\
\mathrm{D}(10) 80-150 \mathrm{~nm} \\
\mathrm{D}(50) 150-250 \mathrm{~nm} \\
\mathrm{D}(90) 250-450 \mathrm{~nm} \\
\text { Span } 0.4-3\end{array}$ & $\begin{array}{l}\text { Adequate size for nasal administration and for the } \\
\text { interaction with immune cells [11] }\end{array}$ \\
\hline Polydispersity & $<0.3$ & $\begin{array}{l}\text { Physicochemical properties that guarantee } \\
\text { reproducibility }\end{array}$ \\
\hline Surface charge & -30 to $-65 \mathrm{mV}$ & $\begin{array}{l}\text { Adequate values to prevent aggregation in the } \\
\text { mucus, and to ensure a longer stability [11] }\end{array}$ \\
\hline Osmolality & $100-200 \mathrm{mOsm} / \mathrm{Kg}$ & Adequate for nasal administration \\
\hline pH & $5-7.5$ & Adequate for nasal administration [52] \\
\hline Dispersibility & $10 \mathrm{~s}$ & For an easy extemporaneous formulation preparation \\
\hline Microbiology & $\begin{array}{l}\text { TAMC: } 10^{2} \mathrm{CFU} / \mathrm{g} \\
\text { TYMC: } 10^{1} \mathrm{CFU} / \mathrm{g} \\
\text { E. coli: Absence/mL }\end{array}$ & Adequate for nasal administration [53] \\
\hline Water content & $\leq 3 \%$ & To avoid API degradation and bacterial growth [54] \\
\hline
\end{tabular}

TAMC, Total Aerobic Microbial Count; TYMC, Total Combined Yeast and Mold Count.

Once the CQAs of the product were selected, the subsequent step was a risk analysis of the impact of different parameters in the CQAs of the formulation [40]. In general, these parameters are related to the characteristics of the starting materials (i.e., polymers, drug, solvents or ratios), the different steps in the manufacturing process (i.e., phase incorporation rates, incubation times or agitation speeds) and also the environmental factors. In this case, an Ishikawa diagram was sketched to illustrate which specific parameters could alter the CQAs of our nanoformulation (Fig. 1). This risk management tool allowed to identify the potential variables that could have a harmful effect on the formulation attributes. Overall, the factors related to the preparation process had to be further monitored and controlled (Fig. 1), and their influence was rigorously analyzed as described in the following section. 


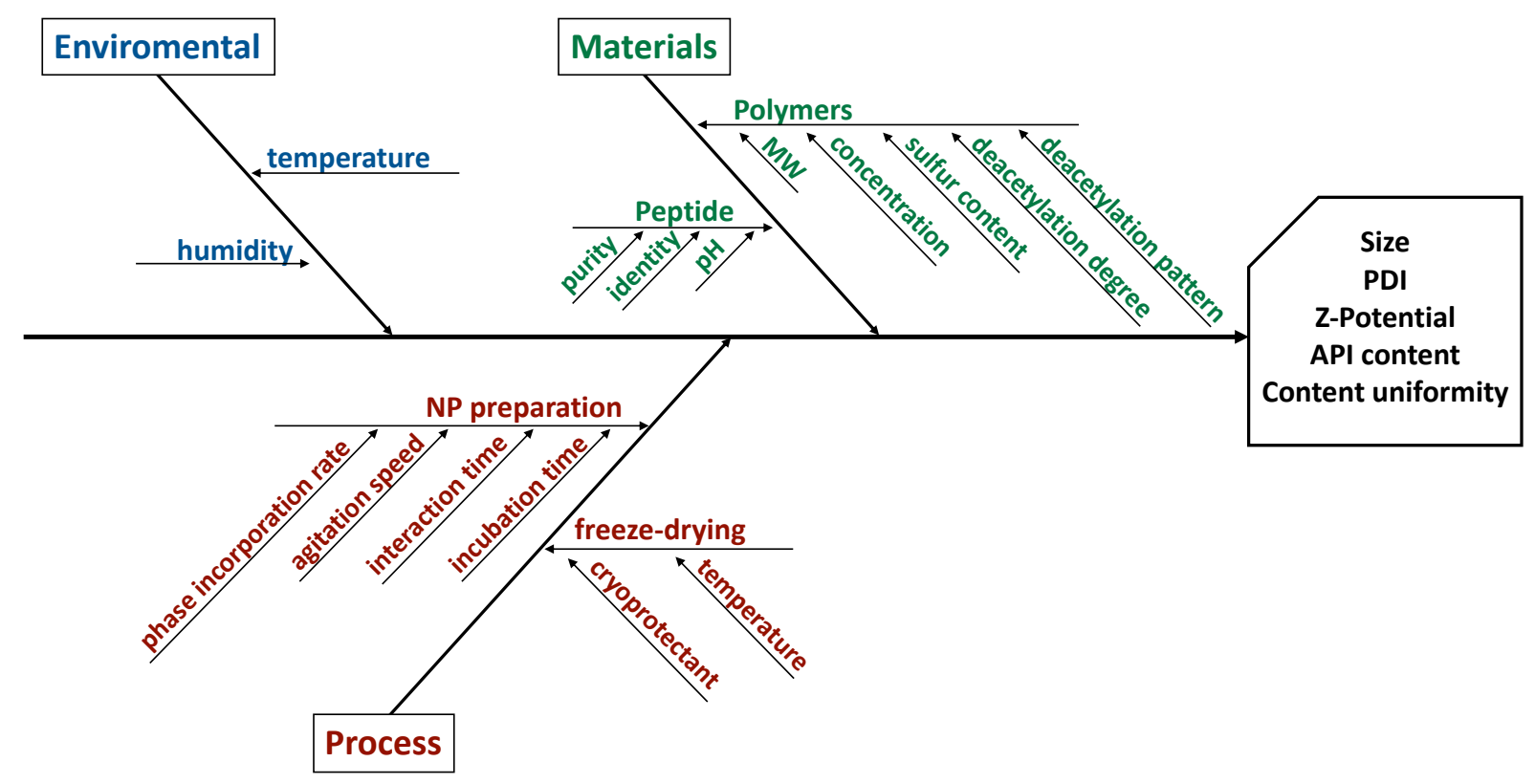

Fig. 1 Ishikawa diagram of the composition and manufacturing factors that influence the quality attributes of the nanoformulation. Interaction time refers to the time that the components are interacting under stirring; while incubation time refers to the same condition, but in the absence of agitation (more details in Figure 2)

\subsection{Nanoparticles fabrication. Determination of the critical process parameters}

NPs were prepared by ionic complexation of the positively charged components (CS and the peptide PCS5) and the negatively charged DS, to a final concentration of $0.31 \mathrm{mg} / \mathrm{ml}$ of CS, $0.13 \mathrm{mg} / \mathrm{mL}$ of PCS5 and $0.94 \mathrm{mg} / \mathrm{mL}$ of DS. The fabrication process of the NPs is represented in Figure 2a. Accordingly, and following the Ishikawa diagram (Fig. 1), we studied how the different formulation steps influenced the final NP properties. Namely, we analyzed how the incorporation rate of DS solution over the CS/PCS5 solution affected the characteristics of the NPs. For this purpose, the DS solution was added dropwise (which would represent a low incorporation rate), with a pipette (medium incorporation rate, as in the original protocol) or using a syringe (to achieve high phase incorporation rates). As shown in Figure $\mathbf{2 b}, \mathbf{c}$, the dropwise incorporation (represented as "low") caused the aggregation of the NPs, with significant changes in particle size and PDI. However, the other two procedures led to particles of adequate physicochemical properties (particle size close to $150 \mathrm{~nm}$, PDI lower than 0.2 and negative surface charges). Other parameters such as the agitation speed of the CS/PCS5 phase while adding DS, the time of interaction with DS, or the incubation time were also evaluated (Fig. 2). All procedures yielded NPs with physicochemical properties similar to the ones produced following the original protocol. 
Overall, the most critical parameter to monitor when translating this manufacturing process will be the incorporation rate of DS over the CS/PCS5 phase, because a low incorporation rate will cause the aggregation of the particles.

a

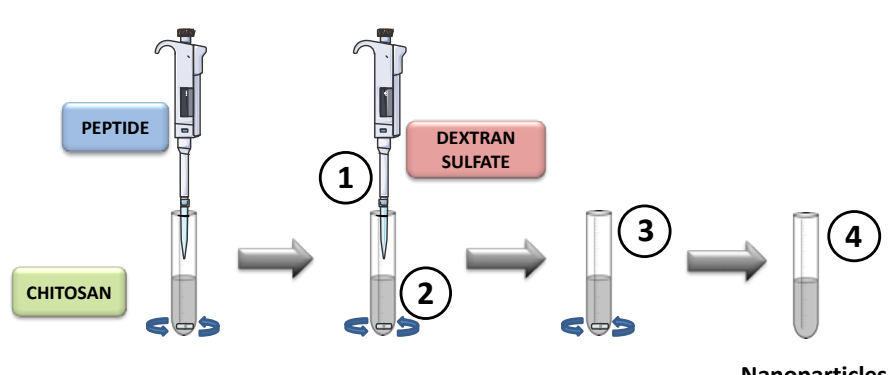

b

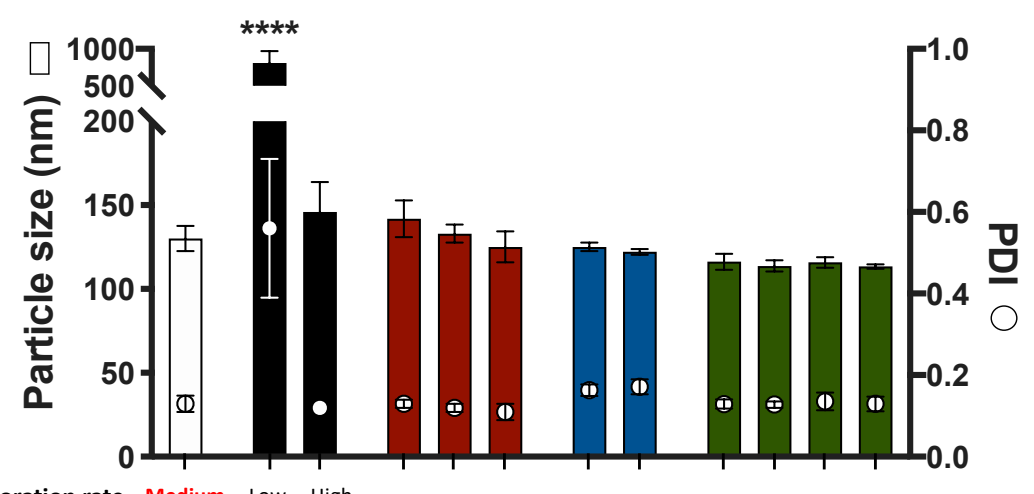

Phase incorporation rate Medium Low High

Agitation speed (rpm) 700

Interaction time $(\mathrm{min}) \quad 5$

Incubation time $(\mathrm{min}) \quad 10$

C

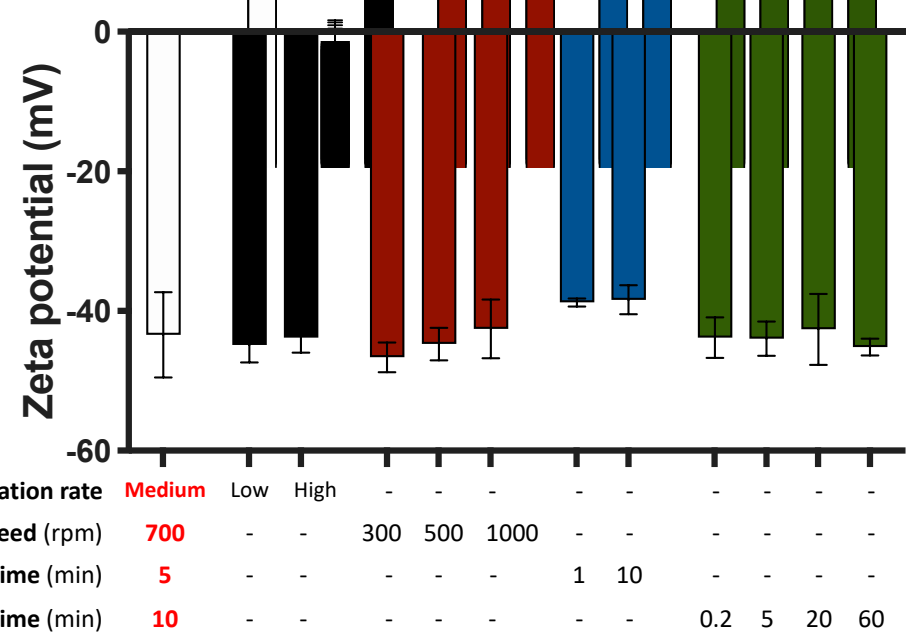

1 Phase incorporation rate

2 Agitation speed

3 Interaction time

4 Incubation time

\section{Original protocol}

Phase incorporation rate

Agitation speed

$\square$ Interaction time

$\square$ Incubation time 
Fig. 2 Nanoparticle manufacturing process and effect of the different steps on the physicochemical properties of the formulation. (a) Fabrication of the nanoparticles. The peptide antigen is added to the chitosan solution. Then, (1; phase incorporation rate) the solution of dextran sulfate is incorporated into the chitosan/peptide solution, (2; agitation speed) under magnetic stirring. (3; interaction time) Components are kept under agitation to allow their interaction, and then (4; incubation time) they are kept for 10 additional min in the absence of agitation. $(B, C)$ Effect of the manufacturing parameters on the physicochemical properties of the nanoparticles. (b) Particle size and PDI, and (c) Zeta-potential values were monitored for the different processes: phase incorporation rate, agitation speed, interaction time and incubation time. Hyphens represent the values that are constant, as in the first column. Values represent mean $\pm S D(n \geq 3)$. A statistical comparison was done using a one-way ANOVA, followed by a Dunnett's multiple comparison test. Significant statistical differences are represented as $* * * *(p<$ 0.0001 ) in comparison to the original protocol

\subsection{Characterization of particle size and size distribution}

The selection of adequate analytical methods for the characterization of nanostructures is a key step in the development of a nanomedicine $[16,55]$. Dynamic light scattering (DLS) techniques are fast and easy methods to determine particle size and polydispersity [56]. For the particles here studied these values were about $120 \mathrm{~nm}$ for size, PDI of 0.2 and negative surface charge (Fig. 3a,d). Nevertheless, this method has several drawbacks, such as a bias towards detecting the larger particles of the sample, limited resolution between subpopulations with similar particle size, or the assumption that the particles are spherical [56]. To overcome these biases, the combination with other complementary orthogonal techniques is highly recommended by specialized organizations such as the European Nanomedicine Characterization Laboratory (EUNCL) or the US National Cancer Institute Nanotechnology Characterization Laboratory ( $\mathrm{NCl}-\mathrm{NCL}$ ), that works jointly with the FDA [57]. Electron microscopy imaging can help identify the shape and geometry of the NPs, as well as confirm their distribution and size in number [57]. Indeed, transmission electron microscopy studies corroborated that the developed NPs were spheres, with sizes in the 100-200 nm range (Fig. 3b,d). NTA analysis, although also based on light scattering, is able to track individual particles, allowing to better distinguish between subpopulations of particles with similar particle size [56]. Here, NTA was used as a complementary technique, confirming the particle size values obtained with the previous methods (Fig. 3c,d). 
a
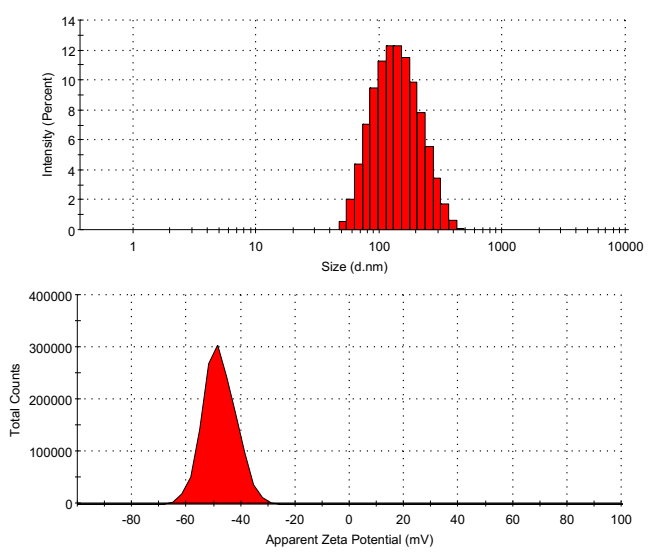

C

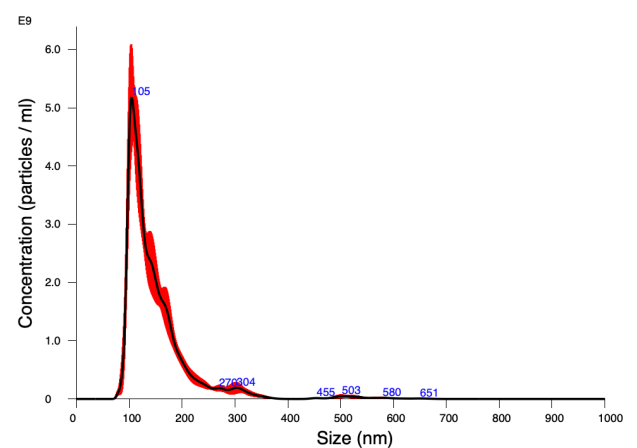

b

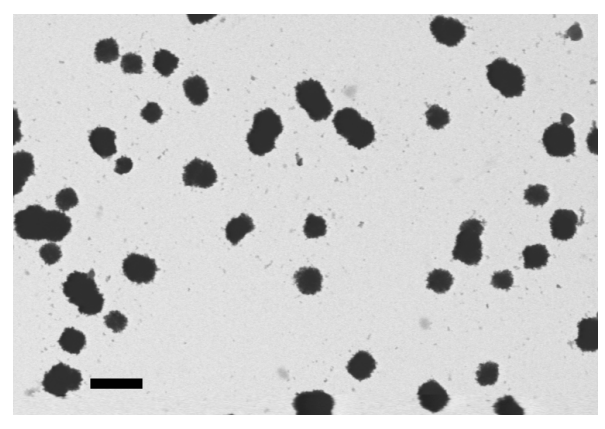

d

\begin{tabular}{|cc|}
\hline Method & Size \pm SD $(\mathbf{n m})$ \\
DLS & $123 \pm 12$ \\
TEM & $127 \pm 38$ \\
NTA & $122 \pm 17$ \\
\hline
\end{tabular}

Fig. 3 Physicochemical characterization of the nanoformulation. (a) DLS intensity histograms (top) and surface charge values (bottom), (b) Micrographs of the NPs by FESEM with the STEM detector (size bar represents 200 $\mathrm{nm}$ ), and (c) NTA size distribution. (d) Summary of the mean size values of the nanoparticles measured by the three complementary techniques evaluated

\subsection{Content uniformity monitorization}

The selection of the adequate methods for the quantification of both the number of NPs and the quantity of drug associated to them is an essential step to guarantee the uniformity of the formulations and their batch-to-batch reproducibility.

\subsubsection{Methods for particle content evaluation}

Derived count rate is a parameter given by DLS measurement that represents the scattering intensity measured in the absence of a laser light attenuation filter, making it a convenient parameter to obtain the particle concentration $[58,59]$. Although it is not a direct measure of the number of particles within the formulation, it can be used as an indirect measurement for the purpose of comparison between batches, and its use is recommended by the EUNCL at the prescreening phases [58]. It is important to bear in mind that in order for this parameter to be accurate, NP size has to remain constant in the 
different particles concentrations tested [59]. In this case, different dilutions of the initial nanoformulation showed a linear correlation $\left(R^{2}>0.998\right)$ with the values of the derived count rate (Supplementary Material, Fig. S1a). Nevertheless, since the lasers of different devices are not identically calibrated, the overall values are not comparable among them (data not shown). Therefore, DLS was a suitable measurement of the content uniformity as an internal control.

The determination of the turbidimetry (values of transmittance) has classically been a way to have a gross estimation of the concentration of particles in suspension, with the premise that particle size also has to remain constant [59]. Using ultrapure water as a blank (100\% transmittance), a linear correlation $\left(R^{2}>0.942\right)$ between the percentage of transmittance and the concentration of the formulation was reported (Supplementary Material, Fig. S1b). Furthermore, the fact that the transmittance values were similar between different laboratories, confirms them as an interlaboratory validation method for the manufacturing process of the nanoformulation.

\subsubsection{Evaluation of the API content}

The determination of the drug content is a parameter that deserves special attention. In this case, an UPLC method to analyze the peptide antigen (PCS5) has already been described [37]. For PCS5 quantification, NPs were, first, disassembled in order to release the peptide. Since NPs were mainly formed through ionic interactions between the two polymers and the peptide (isoelectric points values of: $\left.\mathrm{pl}_{\mathrm{CS}}, 6.5 ; \mathrm{pl}_{\mathrm{DS}},<2 ; \mathrm{pl}_{\mathrm{PCS}}, 11\right)$, the use of a hypertonic medium was expected to disrupt the particles and allow the quantification of the peptide. Indeed, high concentrations of $\mathrm{KCl}(2 \mathrm{M})$ led to the disassociation of the particles, verified by a $100 \%$ recovery of the peptide. This was also confirmed by a dramatic decrease in the derived count rate values (Supplementary Material, Fig. S2a).

Additionally, calibration curves of the peptide in water and in the matrix (blank NPs disrupted with 2M $\mathrm{KCl}$ ) showed no influence of the matrix for the quantification of PCS5, confirming the specificity of the method. Additionally, linear calibration curves with $R^{2}>0.999$ were obtained in both cases (Supplementary Material, Fig. S2b). The accuracy and precision of the method were also confirmed (data not shown).

\subsection{Aseptic manufacturing}

According to FDA regulations, nasal sprays do not need to be sterile for patient administration, nevertheless, the microbial content has to be controlled [53]. To do so, from the different sterilization methods available, we selected filtration as the one to guarantee a low microbial burden [60]. At the 
same time, it is important to bear in mind that having reliable and reproducible methods to reduce the microbial burden is crucial to guarantee the safety of the product. In fact, problems related to the sterilization of Doxil ${ }^{\circledast} /$ Caelyx $^{\circledR}$ were reported in 2011 , and caused an important drug shortage $[22,61]$. The effect of the filter material (PVDF, PES or PTFE) over some CQAs (e.g., particle size and number of particles) was studied in order to select the most adequate filter. It has been described that for an effective filtration through a $0.22 \mu \mathrm{m}$ mesh size filter, particle size should be smaller than $200 \mathrm{~nm}$, preferably bellow $100 \mathrm{~nm}$ [62-64]. The assessment of the value of the filtration process was assayed for the nanoformulation and, although the results showed no significant changes in the particle size when using the different filters (Fig. 4a), a 15-30\% decrease in the derived count rate was observed after filtration (Fig. 4b), indicating that a certain number of NPs did not pass through the filters.
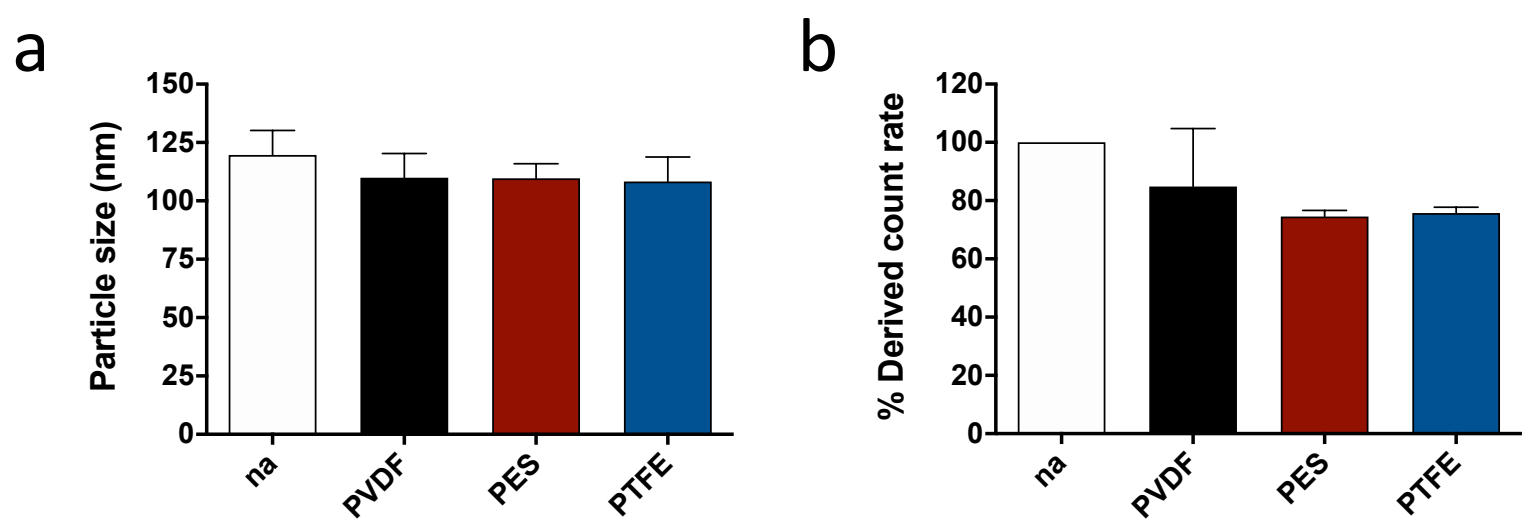

Fig. 4 Effect of NP filtration through different $0.22 \mu \mathrm{m}$ filters in terms of (a) particle size and (b) derived count rate after filtration, in comparison to the non-filtered particles (na). Values represent mean $\pm S D(n=3)$

An alternative procedure to decrease the potential impurities of the NPs would be the filtration of the starting materials. To determine the feasibility of this approach, solutions of CS and DS were filtered through $0.22 \mu \mathrm{m}$ PVDF filters, and then freeze-dried to determine the yield of the process. The recovery yields obtained were $94 \pm 5 \%$ for CS, and $100 \pm 7 \%$ for DS. Furthermore, the NPs formulated with the filtered materials presented the same attributes as the ones with non-filtered components (Supplementary Material, Table S1). Therefore, starting materials could also be filtered to minimize the microbial burden of the final formulation, without modifying any other attributes.

\subsection{Long-term stability of the freeze-dried formulation}

A long-term stability at room temperature is a highly desirable attribute for any vaccine. Having this feature would eliminate the need for the cold chain and would facilitate the accessibility of the vaccine to developing countries. For this purpose, NPs were freeze-dried in order to preserve the formulation 
stability under storage for long periods of time. Trehalose was selected as a cryoprotectant, since its use has been proven to maintain the physicochemical properties of the NPs [37].

The characterization of the NPs by DLS, microscopy, and NTA confirmed that the particle size values of the nanoformulations were barely altered during the freeze-drying process (Supplementary Material, Fig. S3). In fact, a modest increase in particle size by the three techniques was observed. An analysis of the content uniformity yielded transmittance values of $4 \pm 2 \%$; and a peptide recovery of $96 \pm 13 \%$, confirming the stability after the lyophilization process. The resuspended freeze-dried formulation also presented a pH of 6.5, appropriate for nasal administration [52]. Regarding the osmolality, values of approximately $149 \mathrm{mOsm} / \mathrm{Kg}$ were obtained. Finally, the residual moisture after freeze-drying was also tested, providing values lower than $3 \%$, which have been reported to be adequate to avoid unwanted bacterial growth [54].

In agreement with the $\mathrm{ICH}$ guidelines, the evaluation of the long-term stability of the freeze-dried NPs [65], was performed at $5{ }^{\circ} \mathrm{C}$ for simulating the storage in a refrigerator, $25^{\circ} \mathrm{C} / 60 \%$ relative humidity (RH) for a general long-term stability study, and at $40{ }^{\circ} \mathrm{C} / 75 \% \mathrm{RH}$ for an accelerated stability study. Some physicochemical properties (particle size, PDI and Z-potential), API content and pH were monitored over time. All these attributes were found within our specification values for up to 15 months in storage, both for the refrigerator and the general long-term stability conditions (Fig. 5). Only in the case of the accelerated study $\left(40^{\circ} \mathrm{C} / 75 \% \mathrm{RH}\right)$, the $\mathrm{pH}$ value was below the specification range (Fig. 5d), which could be related to the degradation of the components [66].

These results evidence the necessity of establishing and tracking all key attributes to guarantee a good characterization and understanding of the developed nanoformulations. They also underline that the nanovaccine here developed is stable for over a year without the need of the cold chain. 
a

$\square$ Size $40^{\circ} \mathrm{C} \quad \square \operatorname{Size} 25^{\circ} \mathrm{C} \quad \square \operatorname{Size} 4{ }^{\circ} \mathrm{C}$

- $\mathrm{PDI} 40^{\circ} \mathrm{C}$ ○ $\mathrm{PDI} 25^{\circ} \mathrm{C}$ - $\mathrm{PDI} 4^{\circ} \mathrm{C}$

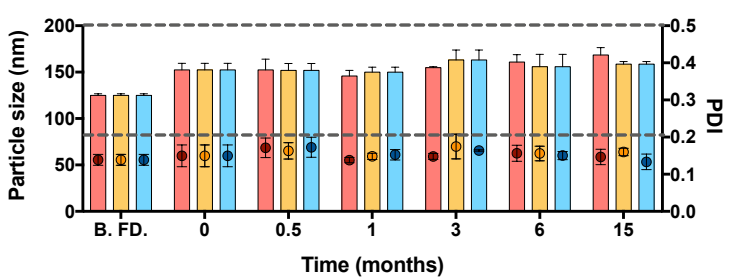

C

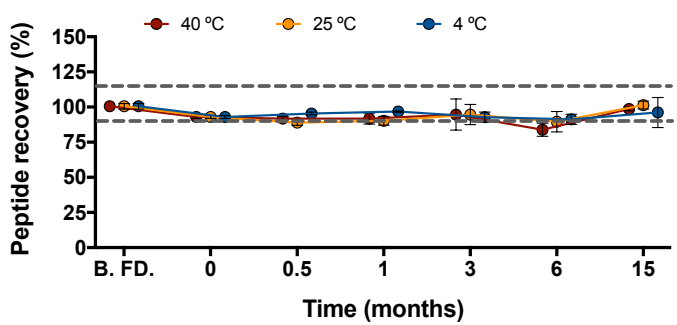

b

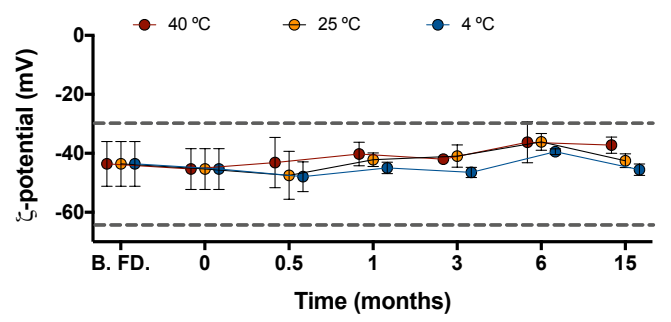

d

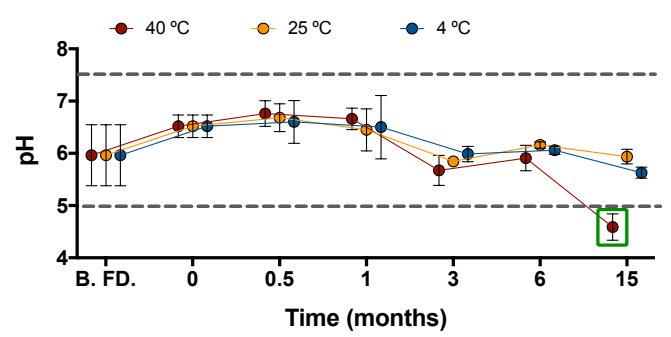

Fig. 5 Long-term stability of the freeze-dried NPs at $5{ }^{\circ} \mathrm{C}$; at $25^{\circ} \mathrm{C} / 60 \% \mathrm{RH}$; and at $40{ }^{\circ} \mathrm{C} / 75 \% \mathrm{RH}$. Evolution of (a) particle size and PDI, (b) zeta-potential, (c) \% of peptide recovery and (d) $\mathrm{pH}$. The red box highlights the values that are not within the CQAs. Values represent mean \pm SD $(n \geq 3)$

\subsection{Technology transfer}

Another important requirement for the good manufacturing of a nanoformulation is to ensure that the production procedure is reproducible with different batches of the forming polymers, as well as across different people and laboratories. First, we compared the physicochemical properties of the NPs prepared with three different batches of CS, and two different batches of DS, confirming the reproducibility of the formulation (Supplementary Material, Table S2). Additionally, the formulation process was transferred to three different laboratories (at the University of Santiago de Compostela, at the CIDETEC Nanomedicine, and at UT2A laboratory), with different personnel, and the resulting batches of loaded NPs (from 1.65 to $200 \mathrm{~mL}$ ) were thoroughly characterized and compared. In all three centers, the physicochemical properties of the different batches were found to be within the specification values previously established in the CQAs (Supplementary Material, Table S3). These results further highlight the suitability of these polymeric NPs for a successful translation from bench to an industrial level.

\subsection{Scaling up by a microfluidic-based and a batch-mode method}

Bearing in mind that the ultimate goal of this nanoformulation development was an industrial translation, a scale-up from the original batch size $(1.65 \mathrm{~mL})$ to a more suitable size for preclinical and 
clinical studies was a fundamental step in this work. Thus, we studied both a continuous and discontinuous scale-up procedure, by the adaptation of microfluidics for the production of the NPs and the preparation of a $200 \mathrm{~mL}$ batch. Finally, a $200-\mathrm{mL}$ batch was produced in the pilot plant under GMPlike conditions.

\subsubsection{Continuous production of the nanoparticles using microfluidics}

Microfluidics has emerged as a potential tool to produce highly reproducible nanoformulations, with the additional advantage of scalability [67]. In this case, a staggered herringbone mixer was employed for the preparation of the NPs [68]. Most nanosystems prepared by this technique are based on the nanoprecipitation of the materials when the organic and aqueous phase meet, while in our case the particle formation relied on the ionic interactions between two oppositely charged phases. The satisfactory application of this technique for a solvent-free NP formation has been recently disclosed for the preparation of octa-arginine/RNA nanocomplexes [69]. Considering that the process parameters may have an important effect in the properties of the resulting NPs [70], here, we first conducted a screening of the influence of the flow rates over the production of blank NPs. Then, the method that provided the best result was applied to the loaded NPs. The cartridge employed consisted on two inlets, one for the positively charged phase and the other for the negative DS phase, followed by a mixing area and finally an outlet to collect the formed NPs (Fig. 6a). Solutions of CS and DS were prepared at the same concentrations as the ones used for smaller batches; the flow ratio was kept constant at 1:1, and the flow rate was the parameter of study (from 0.5 to $14 \mathrm{~mL} / \mathrm{min}$ ).

For the blank NPs, the particle size decreased as the flow rate values were increased, but at the same time, higher variability was detected (Fig. 6b). Interestingly, the higher flow rates also yielded smaller derived count rate values (Fig. 6 c). On the other hand, the lowest flow rate tested $(0.5 \mathrm{~mL} / \mathrm{min}$ ) generated reproducible particles, with properties closer to our nanoformulation CQAs (Fig. 6b,c). In this regard, we have hypothesized that the high flow rates (of $3 \mathrm{~mL} / \mathrm{min}$ or more) might hinder the adequate interaction time between the oppositely charged polymers. This incomplete interaction would lead to a higher amount of free components, resulting in low derived count rate values. When testing these conditions for the loaded NPs, similar physicochemical properties to the ones produced by a discontinuous method were obtained (Fig. $\mathbf{6 d}$ ). Therefore, the nanoformulation of study could be produced with microfluidics, which allows to envisage a continuous and scaled-up production. 
a
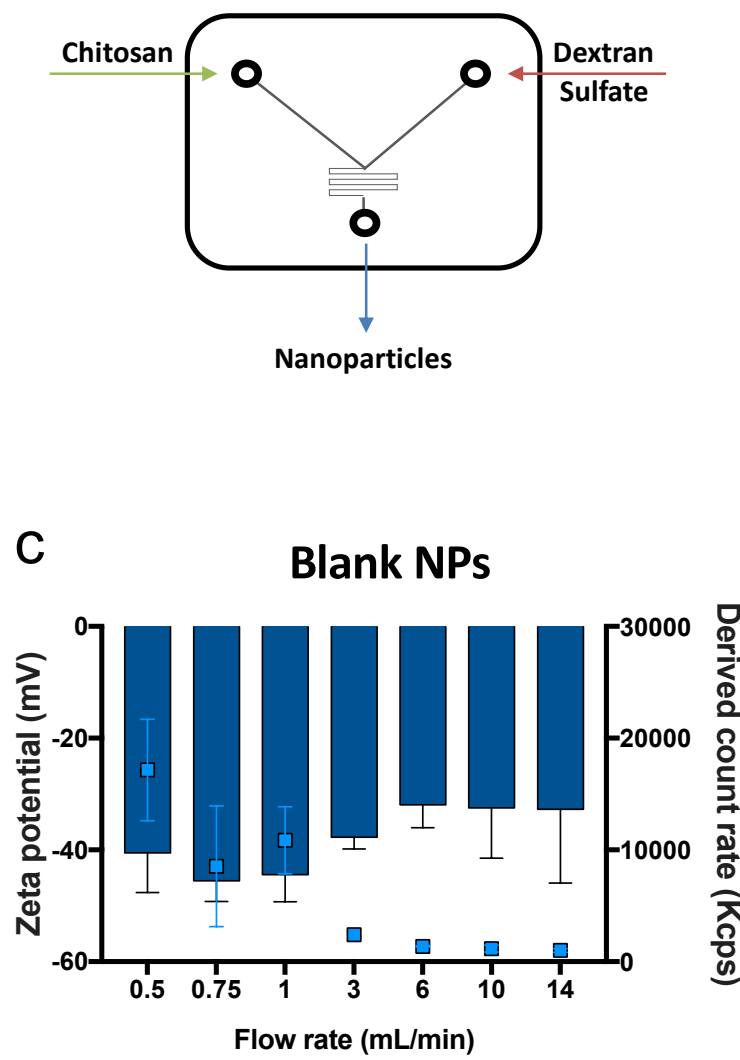

b

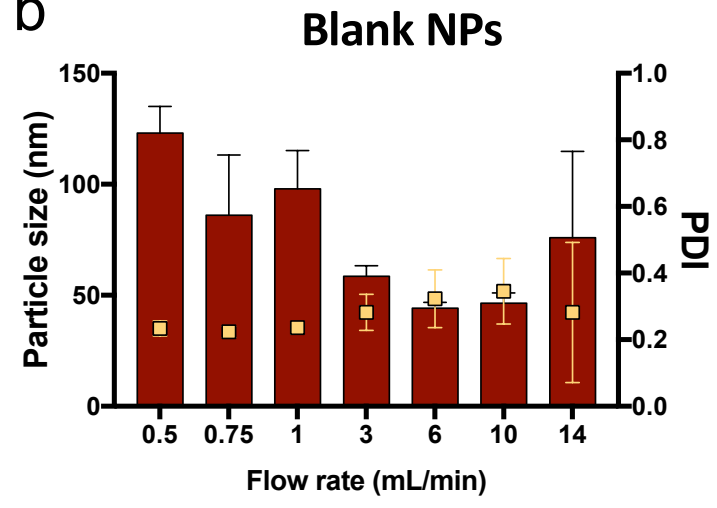

O

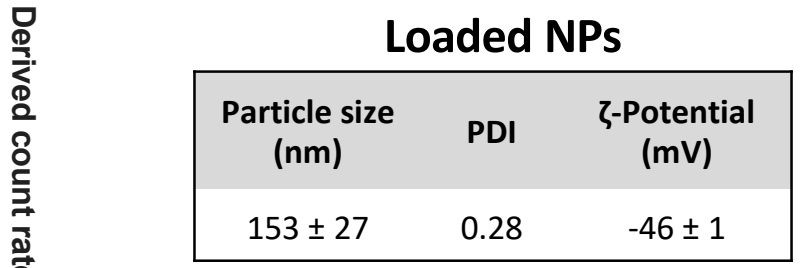

$$
\square \text { Particle size }(\mathrm{nm}) \quad \square \text { PDI } \quad \square \text { Z-Potential (mV) } \quad \text { Derived count rate (Kcps) }
$$

Fig. 6 Scale up using microfluidics. (a) Design of the cartridge used. Influence of the different flow rates in (b) particle size and PDI, and in (c) Z-potential and derived count rate. (d) Physicochemical properties of the loaded NPs prepared with a flow rate of $0.5 \mathrm{~mL} / \mathrm{min}$. Values represent mean \pm SD $(n=3)$. NPs, nanoparticles; PDI, polydispersity index

\subsubsection{Batch mode production of the nanoformulation}

The NPs were prepared by ionic complexation, a method that has been described as easily scalable [71]. In the particular case of the NPs here studied, the magnetic stirring of the small batches was substituted by a mechanical stirring with a blade agitator, more suitable for an accurate control when large volume solutions are mixed. As studied in section 3.2., the most critical parameter to obtain adequate NPs and prevent aggregation was the incorporation rate of the DS solution over the CS/PCS5 phase. Thus, for this scale-up, the mechanical stirring was kept at $700 \mathrm{rpm}$, and the DS solution was poured manually (Supplementary Material, Video S1).

First, $200 \mathrm{~mL}$ batches of blank NPs were prepared to confirm the suitability of the procedure for a larger scale, and then the same procedure was applied to prepare the loaded NPs. Particle size, PDI, Zpotential and $\mathrm{pH}$ were monitored to evaluate the method performance. As shown in Table 3, all values 
were found within the product specifications previously described. Therefore, this discontinuous method was proven to be suitable for the production of large volumes of NPs, with no important effects over any of their physicochemical properties.

Table 3 Physicochemical properties of the scaled-up blank and loaded nanoparticles in comparison with the small-size batches

\begin{tabular}{|lccccc|}
\hline \multicolumn{1}{|c}{ Sample } & Particle size (nm) & PDI & $\zeta$-potential (mV) & pH & Transmittance (\%) \\
\hline $\begin{array}{l}\text { Blank NPs } \\
\text { (1.65 mL batch) } \\
\text { Blank NPs } \\
\text { (200 } \mathrm{mL} \text { batch) }\end{array}$ & $95 \pm 8$ & 0.16 & $-41 \pm 4$ & $7 \pm 0.2$ & $25 \pm 4$ \\
\hline $\begin{array}{l}\text { Loaded NPs } \\
\text { (1.65 } \mathrm{mL} \text { batch) }\end{array}$ & $130 \pm 15$ & 0.14 & $-45 \pm 7$ & $6 \pm 0.6$ & $6 \pm 3$ \\
$\begin{array}{l}\text { Loaded NPs } \\
\text { (200 } \mathrm{mL} \text { batch) }\end{array}$ & $129 \pm 4$ & 0.15 & $-41 \pm 6$ & $6 \pm 0.2$ & $3 \pm 2$ \\
\hline $\begin{array}{l}\text { FD NPs } \\
\text { (1.65 mL batch) }\end{array}$ & $160 \pm 15$ & 0.16 & $-43 \pm 7$ & $7 \pm 0.6$ & $4 \pm 2$ \\
$\begin{array}{l}\text { FD NPs } \\
\text { (200 } \mathrm{mL} \text { batch) }\end{array}$ & $182 \pm 11$ & 0.19 & $-45 \pm 3$ & $6 \pm 0.7$ & $3 \pm 2$ \\
\hline
\end{tabular}

Values represent mean $\pm S D$ ( $n \geq 3$; except for loaded and FD NPs $200 \mathrm{ml}$ batch, where $n=2)$

$F D$, freeze-dried; PDI, polydispersity index; NPs, nanoparticles

We have seen in this section that the formulation of CS/DS NPs can be translated to an industrial environment and fabricated either by discontinuous (batch-mode) or continuous (microfluidics) methods. In the case of the batch-mode preparation, it is a simple and fast method, that may need subsequent adaptations with the increase in the batch size. On the other hand, microfluidics is a very reproducible technique that can produce high NP volumes by using several cartridges in a row. Nevertheless, these cartridges are costly, and have a limited lifetime and re-usability, thus increasing the final cost of fabrication. These aspects have to be taken into consideration when selecting the methods for an industrial translation.

\subsubsection{Production of a GMP-like batch in the pilot plant}

As the last step on the road to the translation of the nanomedicine, a $200 \mathrm{~mL}$ batch volume was selected to be prepared in the pilot plant. This batch size, equivalent to 220 doses of the vaccine candidate, was considered to be sufficient for an exploratory preclinical study with 50 non-human primates and four boosts per animal. Furthermore, all the procedures in the pilot plant were conducted under GMP-like conditions. In this regard, production processes, materials and personal flow were designed in qualified facilities according to GMP guidelines. All the components used to 
prepare the formulation were qualified as GMP grade materials, with the exception of the peptide antigen. To prepare the GMP-like batch, the starting polymer solutions (CS and DS) were first filtered through $0.2 \mu \mathrm{m}$ mesh size filters, as described in section 3.5. Then, the formulation was prepared under mechanical stirring with a blade agitator. Subsequently, formulation and cryoprotectant were added to type I glass vials, to then be freeze-dried. The resulting formulation was redispersed in highly purified water and characterized. The physicochemical properties of the NPs were found within the CQAs previously described (Table 4). Therefore, the translation of the nanovaccine from the bench to an industrial environment has been successfully achieved.

Table 4 Physicochemical properties of the nanovaccine fabricated in the pilot plant

\begin{tabular}{|ccccccc|}
\hline Sample & $\begin{array}{c}\text { Particle size } \\
(\mathrm{nm})\end{array}$ & PDI & $\begin{array}{c}\zeta \text {-potential } \\
(\mathrm{mV})\end{array}$ & pH & $\begin{array}{c}\text { Transm } \\
(\%)\end{array}$ & $\begin{array}{c}\text { Osmolality } \\
(\mathrm{mOsm} / \mathrm{kg})\end{array}$ \\
\hline Final formulation & $150 \pm 1$ & 0.13 & $-42 \pm 1$ & 6.6 & 7.2 & 186 \\
\hline
\end{tabular}

FD, freeze-drying; PDI, polydispersity index; NPs, nanoparticles; transm, transmittance

Overall, we consider that this work compiles in a great manner with the MIRIBEL recommendations for material characterization [31]. Here, we have provided a detailed description of the synthesis method of the formulation, together with an evaluation of the different parameters that may have an effect on the final NPs. Furthermore, the values of size, shape, zeta potential, density, concentration and drug loading were thoroughly studied and reported in this work, and in many cases confirmed by several complementary techniques. Besides, three different batches of the forming components have been employed to guarantee the reproducibility of the formulation, among other aspects. Overall, the results of this manuscript compile with the MIRIBEL recommendations, which we hope will help in the standardization and application of stablished methodologies for the characterization of nanosystems.

\section{Conclusions}

In this work, we demonstrated the feasibility to manufacture an potential HIV nanovaccine candidate in a pilot plant. By implementing a QbD approach, the most critical aspects of the process that have an impact on the formulation attributes were highlighted. This strategy helped to identify that the phase incorporation rate had the most significant effect over the final properties of the nanoformulation. In addition, we emphasized the importance of combining orthogonal techniques to guarantee a realistic and complete characterization of the formulation. The definition of all these critical process parameters led to the successful transfer of the HIV nanovaccine manufacturing procedure from the laboratory to the pilot plant production, and its scale-up by both the microfluidic and the batch mode 
methods. All these results validate that the nanomedicine would be ready to move towards an industrial manufacturing set up.

\section{Conflict of interest}

The authors declare that they have no conflict of interest.

\section{Acknowledgments}

This work was supported by the European Union's Horizon 2020 research program (NanoPilot project - grant agreement number 646142) and by Xunta de Galicia's Grupos de referencia competitiva (grant number ED431C 2017/09). T.G. Dacoba acknowledges a predoctoral FPU grant from the Spanish Ministry of Education, Culture and Sports (grant number FPU14/05866). Authors would like to thank the RIAIDT-USC analytical facilities, for the microscopy imaging. 


\section{References}

1. Niu Z, Conejos-Sánchez I, Griffin BT, O’Driscoll CM, Alonso MJ. Lipid-based nanocarriers for oral peptide delivery. Adv Drug Deliv Rev. 2016;106:337-54.

2. Yu M, Wu J, Shi J, Farokhzad OC. Nanotechnology for protein delivery: overview and perspectives. J Control Release. 2016;240:24-37.

3. Santalices I, Gonella A, Torres D, Alonso MJ. Advances on the formulation of proteins using nanotechnologies. J Drug Deliv Sci Technol. 2017;42:155-80.

4. Samaridou E, Alonso MJ. Nose-to-brain peptide delivery - the potential of nanotechnology. Bioorg Med Chem. 2018;26:2888-905.

5. Li Z, Rana TM. Therapeutic targeting of microRNAs: current status and future challenges. Nat Rev Drug Discov. 2014;13:622-38.

6. Liu Y, Xu C-F, Iqbal S, Yang X-Z, Wang J. Responsive nanocarriers as an emerging platform for cascaded delivery of nucleic acids to cancer. Adv Drug Deliv Rev. 2017;115:98-114.

7. Saraiva SM, Castro-López V, Pañeda C, Alonso MJ. Synthetic nanocarriers for the delivery of polynucleotides to the eye. Eur J Pharm Sci. 2017;103:5-18.

8. Kaczmarek JC, Kowalski PS, Anderson DG. Advances in the delivery of RNA therapeutics: from concept to clinical reality. Genome Med. 2017;9:60.

9. Irvine DJ, Hanson MC, Rakhra K, Tokatlian T. Synthetic nanoparticles for vaccines and immunotherapy. Chem Rev. 2015;115:11109-46.

10. Cordeiro AS, Alonso MJ. Recent advances in vaccine delivery. Pharm Pat Anal. 2015;5:49-73.

11. Dacoba TG, Olivera A, Torres D, Crecente-Campo J, Alonso MJ. Modulating the immune system through nanotechnology. Semin Immunol. 2017;34:78-102.

12. Gause KT, Wheatley AK, Cui J, Yan Y, Kent SJ, Caruso F. Immunological principles guiding the rational design of particles for vaccine delivery. ACS Nano. 2017;11:54-68.

13. Bobo D, Robinson KJ, Islam J, Thurecht KJ, Corrie SR. Nanoparticle-based medicines: a review of FDA-approved materials and clinical trials to date. Pharm Res. 2016;33:2373-87.

14. Anselmo AC, Mitragotri S. Nanoparticles in the clinic. Bioeng Transl Med. 2016;1:10-29.

15. Ventola CL. Progress in nanomedicine: approved and investigational nanodrugs. P T. 2017;42:742-55.

16. Desai N. Challenges in development of nanoparticle-based therapeutics. AAPS J. 2012;14:282-95.

17. Ragelle H, Danhier F, Préat V, Langer R, Anderson DG. Nanoparticle-based drug delivery systems: a commercial and regulatory outlook as the field matures. Expert Opin Drug Deliv. 2017;14:851-64.

18. Hua S, de Matos MBC, Metselaar JM, Storm G. Current trends and challenges in the clinical translation of nanoparticulate nanomedicines: pathways for translational development and commercialization. Front Pharmacol. 2018;9:1-14.

19. Dormont F, Rouquette M, Mahatsekake C, Gobeaux F, Peramo A, Brusini R, et al. Translation of nanomedicines from lab to industrial scale synthesis: the case of squalene-adenosine nanoparticles. J Control Release. 2019;307:302-14.

20. Gabizon A, Bradbury M, Prabhakar U, Zamboni W, Libutti S, Grodzinski P. Cancer nanomedicines: closing the translational gap. Lancet. 2014;384:2175-6.

21. Yu LX, Amidon G, Khan MA, Hoag SW, Polli J, Raju GK, et al. Understanding pharmaceutical quality by design. AAPS J. 2014;16:771-83.

22. Wicki A, Witzigmann D, Balasubramanian V, Huwyler J. Nanomedicine in cancer therapy: challenges, opportunities, and clinical applications. J Control Release. 2015;200:138-57.

23. Agrahari V, Agrahari V. Facilitating the translation of nanomedicines to a clinical product: challenges and opportunities. Drug Discov Today. 2018;23:974-91.

24. Zamboni WC, Torchilin V, Patri AK, Hrkach J, Stern S, Lee R, et al. Best practices in cancer nanotechnology: perspective from NCI nanotechnology alliance. Clin Cancer Res. 2012;18:3229-41.

25. Pallagi E, Ambrus R, Szabó-Révész P, Csóka I. Adaptation of the quality by design concept in early pharmaceutical development of an intranasal nanosized formulation. Int J Pharm. 2015;491:384-92.

26. Rose F, Wern JE, Ingvarsson PT, van de Weert M, Andersen P, Follmann F, et al. Engineering of a novel adjuvant based on lipid-polymer hybrid nanoparticles: a quality-by-design approach. J Control Release. 2015;210:48-57.

27. Shah B, Khunt D, Bhatt $H$, Misra M, Padh $H$. Intranasal delivery of venlafaxine loaded nanostructured lipid carrier: risk assessment and QbD based optimization. J Drug Deliv Sci Technol. 2016;33:37-50. 
28. Raina H, Kaur S, Jindal AB. Development of efavirenz loaded solid lipid nanoparticles: risk assessment, qualityby-design $(\mathrm{QbD})$ based optimisation and physicochemical characterisation. J Drug Deliv Sci Technol. 2017;39:180-91.

29. Marto J, Ruivo E, Lucas SD, Gonçalves LM, Simões S, Gouveia LF, et al. Starch nanocapsules containing a novel neutrophil elastase inhibitor with improved pharmaceutical performance. Eur J Pharm Biopharm. 2018;127:1-11.

30. Simões A, Veiga F, Figueiras A, Vitorino C. A practical framework for implementing quality by design to the development of topical drug products: nanosystem-based dosage forms. Int J Pharm. 2018;548:385-99.

31. Faria M, Björnmalm M, Thurecht KJ, Kent SJ, Parton RG, Kavallaris M, et al. Minimum information reporting in bio-nano experimental literature. Nat Nanotechnol. 2018;13:777-85.

32. Vicente S, Peleteiro M, Díaz-Freitas B, Sanchez A, González-Fernández Á, Alonso MJ. Co-delivery of viral proteins and a TLR7 agonist from polysaccharide nanocapsules: a needle-free vaccination strategy. J Control Release. 2013;172:773-81.

33. Correia-Pinto JF, Csaba N, Schiller J, Alonso MJ. Chitosan-poly (I:C)-PADRE based nanoparticles as delivery vehicles for synthetic peptide vaccines. Vaccines. 2015;3:730-50.

34. González-Aramundiz JV, Presas E, Dalmau-Mena I, Martínez-Pulgarín S, Alonso C, Escribano JM, et al. Rational design of protamine nanocapsules as antigen delivery carriers. J Control Release. 2017;245:62-9.

35. Crecente-Campo J, Lorenzo-Abalde S, Mora A, Marzoa J, Csaba N, Blanco J, et al. Bilayer polymeric nanocapsules: a formulation approach for a thermostable and adjuvanted E. coli antigen vaccine. J Control Release. 2018;286:20-32.

36. Li H, Nykoluk M, Li L, Liu LR, Omange RW, Soule G, et al. Natural and cross-inducible anti-SIV antibodies in Mauritian cynomolgus macaques. PLoS One. 2017;12:e0186079.

37. Dacoba TG, Omange RW, Li H, Crecente-Campo J, Luo M, Alonso MJ. Polysaccharide nanoparticles can efficiently modulate the immune response against an HIV peptide antigen. ACS Nano. 2019;13:4947-59.

38. Li H, Omange RW, Liang B, Toledo N, Hai Y, Liu LR, et al. A novel vaccine targeting the viral protease cleavage sites protects Mauritian cynomolgus macaques against vaginal SIVmac251 infection. bioRxiv. 2019;

39. Rathore AS, Winkle H. Quality by design for biopharmaceuticals. Nat Biotechnol. 2009;27:26-34.

40. European Medicines Agency. ICH guideline Q8 (R2) on pharmaceutical development [Internet]. 2017 [cited 2019 Dec 5]. Available from: http://www.ema.europa.eu/docs/en_GB/document_library/Scientific_guideline/2009/09/WC500002872.p df

41. International Organization for Standardization. Particle size analysis - Dynamic light scattering (DLS) (ISO/DIS Standard No. 22412). 2017.

42. Hartig SM. Basic image analysis and manipulation in ImageJ. Curr Protoc Mol Biol. 2013;102:1-12.

43. Klein M, Menta M, Dacoba TG, Crecente-Campo J, Alonso MJ, Dupin D, et al. Advanced nanomedicine characterization by DLS and AF4-UV-MALS: application to a HIV nanovaccine. J Pharm Biomed Anal. 2020;179:113017.

44. Rapalli VK, Khosa A, Singhvi G, Girdhar V, Jain R, Dubey SK. Application of QbD principles in nanocarrier-based drug delivery systems. In: Beg S, Hasnain MS, editors. Pharm Qual by Des. Elsevier; 2019. p. 255-96.

45. Li H, Omange RW, Plummer FA, Luo M. A novel HIV vaccine targeting the protease cleavage sites. AIDS Res Ther. 2017;14:51.

46. Cordeiro AS, Alonso MJ, de la Fuente M. Nanoengineering of vaccines using natural polysaccharides. Biotechnol Adv. 2015;33:1279-93.

47. Prego C, Paolicelli P, Díaz B, Vicente S, Sánchez A, González-Fernández Á, et al. Chitosan-based nanoparticles for improving immunization against hepatitis B infection. Vaccine. 2010;28:2607-14.

48. Rose F, Wern JE, Gavins F, Andersen P, Follmann F, Foged C. A strong adjuvant based on glycol-chitosancoated lipid-polymer hybrid nanoparticles potentiates mucosal immune responses against the recombinant Chlamydia trachomatis fusion antigen CTH522. J Control Release. 2018;271:88-97.

49. Sharma S, Mukkur TK, Benson HA, Chen Y. Enhanced immune response against Pertussis toxoid by IgA-loaded chitosan-dextran sulfate nanoparticles. J Pharm Sci. 2012;101:233-44.

50. Correia-Pinto JF, Csaba N, Alonso MJ. Vaccine delivery carriers: insights and future perspectives. Int J Pharm. 2013;440:27-38.

51. Stano A, Nembrini C, Swartz MA, Hubbell JA, Simeoni E. Nanoparticle size influences the magnitude and quality of immune response after intranasal immunization. Vaccine. 2012;30:7541-6.

52. England RJA, Homer JJ, Knight LC, Ell SR. Nasal pH measurement: a reliable and repeatable parameter. Clin 
Otolaryngol. 1999;24:67-8.

53. U.S. Food and Drug Administration. Guidance for industry: nasal spray and inhalation solution, suspension, and spray drug products - chemistry, manufacturing, and controls documentation [Internet]. 2002 [cited 2019 Dec 1]. Available from: https://www.fda.gov/media/70857/download

54. May JC, Wheeler RM, Etz N, Del Grosso A. Measurement of final container residual moisture in freeze-dried biological products. Dev Biol Stand. 1992;74:153-64.

55. Kaur IP, Kakkar V, Deol PK, Yadav M, Singh M, Sharma I. Issues and concerns in nanotech product development and its commercialization. J Control Release. 2014;193:51-62.

56. Maguire CM, Rösslein M, Wick P, Prina-Mello A. Characterisation of particles in solution - a perspective on light scattering and comparative technologies. Sci Technol Adv Mater. 2018;19:732-45.

57. Caputo F, Clogston J, Calzolai L, Rösslein M, Prina-Mello A. Measuring particle size distribution of nanoparticle enabled medicinal products, the joint view of EUNCL and NCI-NCL. A step by step approach combining orthogonal measurements with increasing complexity. J Control Release. 2019;299:31-43.

58. European Nanomedicine Characterisation Laboratory. Measuring batch mode DLS [Internet]. 2016 [cited 2019 Dec 5]. Available from: http://www.euncl.eu/about-us/assay-cascade/PDFs/Prescreening/EUNCL-PCC001.pdf?m=1468937875\&

59. Shang J, Gao X. Nanoparticle counting: towards accurate determination of the molar concentration. Chem Soc Rev. 2014;43:7267-78.

60. Lakkireddy HR, Bazile D. Building the design, translation and development principles of polymeric nanomedicines using the case of clinically advanced poly(lactide(glycolide))-poly(ethylene glycol) nanotechnology as a model: an industrial viewpoint. Adv Drug Deliv Rev. 2016;107:289-332.

61. European Medicines Agency. Questions and answers on the supply situation of Caelyx [Internet]. 2013 [cited 2019 Dec 5]. Available from: http://www.ema.europa.eu/docs/en_GB/document_library/Medicine_QA/2013/04/WC500142510.pdf

62. Vetten MA, Yah CS, Singh T, Gulumian M. Challenges facing sterilization and depyrogenation of nanoparticles: effects on structural stability and biomedical applications. Nanomedicine Nanotechnology, Biol Med. 2014;10:1391-9.

63. Tsukada Y, Hara K, Bando Y, Huang CC, Kousaka Y, Kawashima Y, et al. Particle size control of poly(DL-lactideco-glycolide) nanospheres for sterile applications. Int J Pharm. 2009;370:196-201.

64. Masson V, Maurin F, Fessi H, Devissaguet JP. Influence of sterilization processes on poly( $\varepsilon$-caprolactone) nanospheres. Biomaterials. 1997;18:327-35.

65. U.S. Food and Drug Administration. Guidance for industry Q1A(R2) stability testing of new drug substances and products [Internet]. ICH Guidel. 2003 [cited 2019 Dec 5]. Available from: https://www.fda.gov/media/71707/download

66. Szymańska E, Winnicka K. Stability of chitosan - a challenge for pharmaceutical and biomedical applications. Mar Drugs. 2015;13:1819-46.

67. Valencia PM, Farokhzad OC, Karnik R, Langer R. Microfluidic technologies for accelerating the clinical translation of nanoparticles. Nat Nanotechnol. 2012;7:623.

68. Stroock AD. Chaotic mixer for microchannels. Science. 2002;295:647-51.

69. Samaridou E, Walgrave H, Salta E, Álvarez DM, Castro-López V, Loza M, et al. Nose-to-brain delivery of enveloped RNA - cell permeating peptide nanocomplexes for the treatment of neurodegenerative diseases. Biomaterials. 2020;230:119657.

70. Roces CB, Christensen D, Perrie Y. Translating the fabrication of protein-loaded poly(lactic-co-glycolic acid) nanoparticles from bench to scale-independent production using microfluidics. Drug Deliv Transl Res. 2020;

71. Paliwal R, Babu RJ, Palakurthi S. Nanomedicine scale-up technologies: feasibilities and challenges. AAPS PharmSciTech. 2014;15:1527-34. 


\section{Supplementary Material}

a

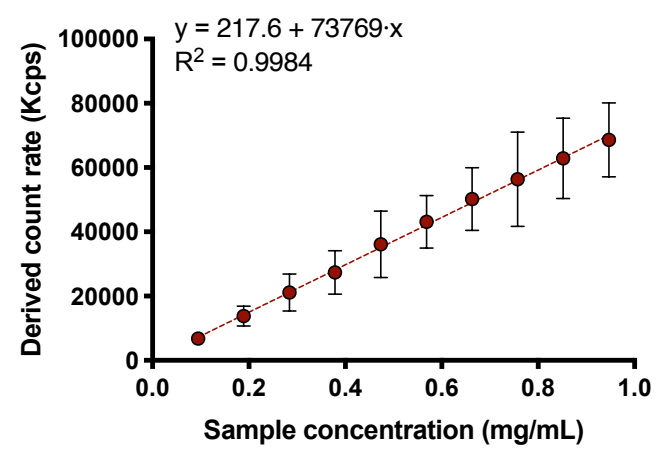

b

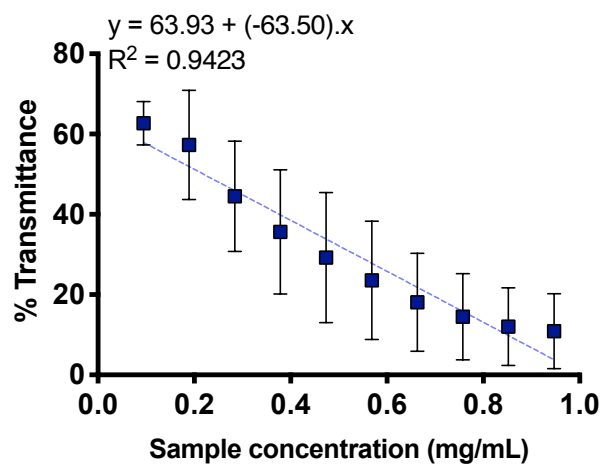

Supplementary Fig. S1 Calibration curves for the determination of nanoparticle content using (a) the values of the derived count rate and (b) the \% of transmittance. Values represent mean $\pm S D(n \geq 3)$

a

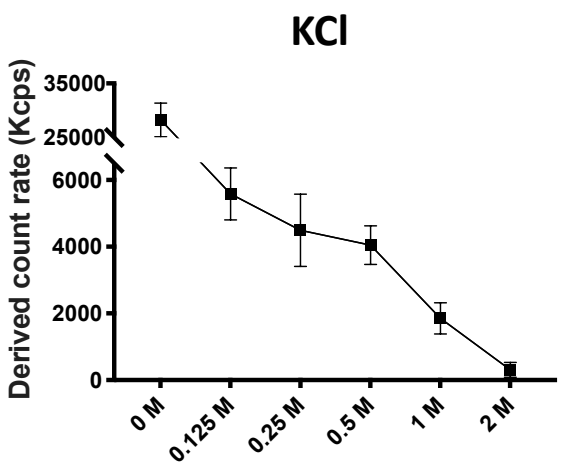

b

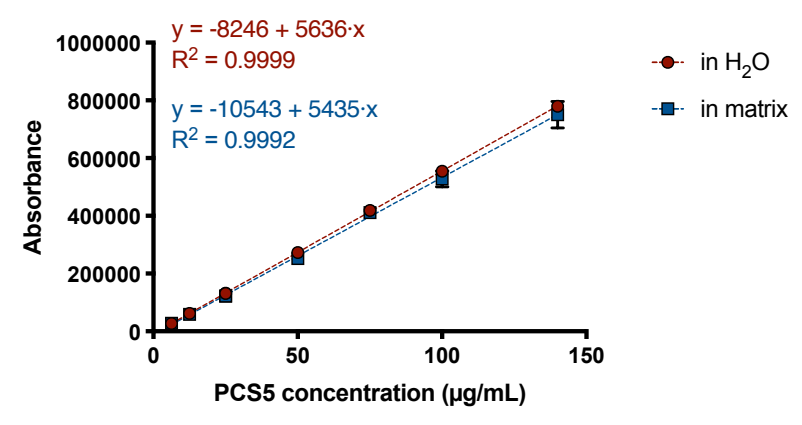

Supplementary Fig. S2 Nanoparticle disassembling in the presence of high ionic strength solutions. (a) Effect of the concentration of $\mathrm{KCl}$ on the derived count rate. (b) Calibration curves of the peptide PCS5 in water (red) and in NPs disrupted with $\mathrm{KCl}$ (matrix, in dark blue). Values represent mean $\pm \mathrm{SD}(\mathrm{n}=3)$ 
a
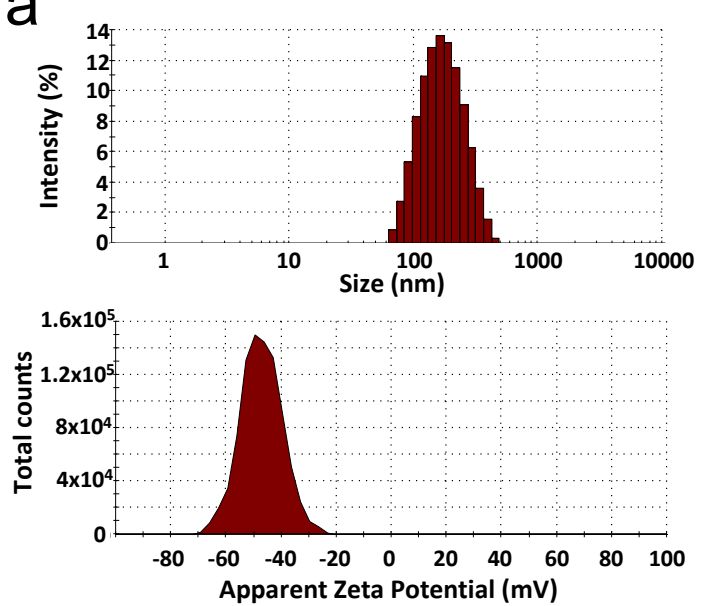

C

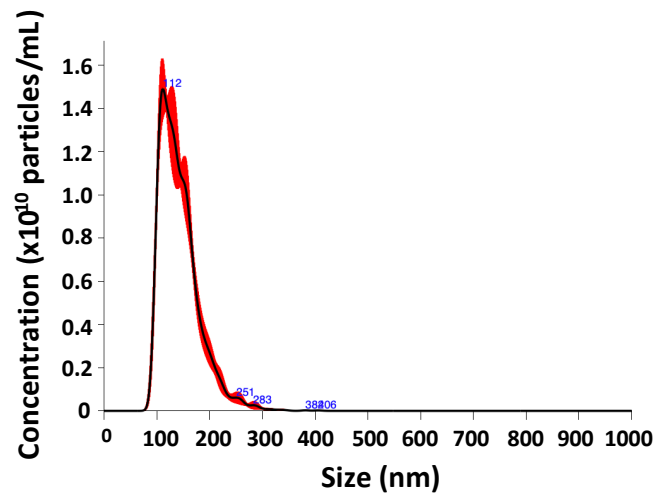

b

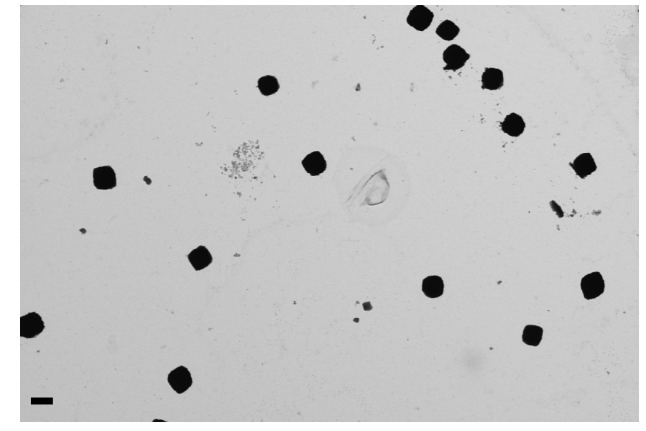

d

\begin{tabular}{|cc|}
\hline Method & Size \pm SD $(\mathbf{n m})$ \\
DLS & $160 \pm 15$ \\
TEM & $187 \pm 57$ \\
NTA & $144 \pm 12$ \\
\hline
\end{tabular}

Supplementary Fig. S3 Physicochemical characterization of the redispersed freeze-dried nanoparticles. (a) DLS intensity histograms (top) and surface charge vaules (bottom), (b) Micrographs of the NPs by FESEM with the STEM detector (size bar represents $200 \mathrm{~nm}$ ), and (c) NTA size distribution. (d) Summary of the mean size values of the nanoparticles measured by the three complementary techniques evaluated 
Supplementary Table S1 Comparison of the physicochemical properties of the nanoparticles prepared with nonfiltered and filtered starting materials

\begin{tabular}{|lllll|}
\hline Starting materials & Particle size $(\mathbf{n m})$ & PDI & Z-potential $(\mathbf{m V})$ & Derived count rate (kcps) \\
Non-filtered & $138 \pm 14$ & 0.14 & $-53 \pm 4$ & $65300 \pm 1900$ \\
Filtered & $135 \pm 12$ & 0.15 & $-50 \pm 3$ & $51500 \pm 1600$
\end{tabular}

PDI, polydispersity index

Supplementary Table S2 Comparison of the physicochemical properties of the nanoparticles prepared with different batches of chitosan and dextran sulfate

\begin{tabular}{|ccccc|}
\hline CS batch & DS batch & Particle size $(\mathrm{nm})$ & PDI & Z-potential $(\mathrm{mV})$ \\
batch 1 & batch 1 & $118 \pm 7$ & 0.15 & $-45 \pm 5$ \\
batch 2 & batch 1 & $135 \pm 4$ & 0.14 & $-41 \pm 1$ \\
batch 2 & batch 2 & $113 \pm 9$ & 0.12 & $-46 \pm 2$ \\
batch 3 & batch 2 & $128 \pm 4$ & 0.14 & $-46 \pm 2$ \\
\hline
\end{tabular}

CS, chitosan; DS, dextran sulfate; PDI, polydispersity index 
Supplementary Table S3 Comparison of the physicochemical properties of the resuspended nanoparticles prepared in three different laboratories with the established specifications (CQAs)

\begin{tabular}{|c|c|c|c|c|c|c|c|c|c|c|}
\hline Lab & $\begin{array}{l}\text { Particle size } \\
\text { (nm) }\end{array}$ & PDI & 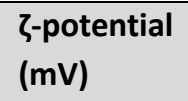 & $\begin{array}{l}\text { Content per } \\
\text { vial }(\mathrm{mg})\end{array}$ & $\mathrm{pH}$ & $\begin{array}{l}\text { Osmolality } \\
\text { (mOsm/Kg) }\end{array}$ & Transm (\%) & Dispersibility & $\begin{array}{l}\text { Residual } \\
\text { moisture (\%) }\end{array}$ & $\begin{array}{l}\text { Peptide } \\
\text { recovery (\%) }\end{array}$ \\
\hline CQAs & $\begin{array}{l}100-300 \\
D(10) 80-150 \\
D(50) 150-250 \\
D(90) 250-450 \\
\text { Span } 0.4-3\end{array}$ & $<0.3$ & $-30--65$ & $82.245 \pm 10 \%$ & $5-7.5$ & 100-200 & $<10 \%$ & Yes & $<5 \%$ & $90-110 \%$ \\
\hline USC & $\begin{array}{l}164 \pm 24 \\
D(10) 99 \pm 10 \\
D(50) 171 \pm 17 \\
D(90) 308 \pm 44 \\
\text { Span } 1.2 \pm 0.2\end{array}$ & 0.16 & $-43 \pm 7$ & $75.6 \pm 0.5 \%$ & $7 \pm 0.6$ & $149 \pm 4$ & $4 \pm 2 \%$ & Yes & n.d. & $96 \pm 13 \%$ \\
\hline $\begin{array}{l}\text { UT2A } \\
{[1]}\end{array}$ & $\begin{array}{l}181 \pm 6 \\
D(10) 139 \pm 6 \\
D(50) 229 \pm 12 \\
D(90) 377 \pm 34 \\
\text { Span } 1.1 \pm 0.1\end{array}$ & 0.17 & n.d. & n.d. & n.d. & n.d. & n.d. & Yes & n.d. & $110 \pm 2 \%$ \\
\hline CIDETEC & $\begin{array}{l}157 \pm 17 \\
D(10) 96 \pm 11 \\
D(50) 170 \pm 8 \\
D(90) 309 \pm 4 \\
\text { Span } 1.3 \pm 0.2\end{array}$ & 0.17 & $-45 \pm 7$ & n.d. & $6 \pm 1$ & $154 \pm 6$ & $5 \pm 2 \%$ & Yes & $1 \pm 0.4$ & $100 \pm 4 \%$ \\
\hline
\end{tabular}

n.d., not determined; PDI, polydispersity index; Transm, transmittance

\section{References}

1. Klein M, Menta M, Dacoba TG, Crecente-Campo J, Alonso MJ, Dupin D, et al. Advanced nanomedicine characterization by DLS and AF4-UV-MALS: application to a HIV nanovaccine. J Pharm Biomed Anal. 2020;179:113017. 
